\title{
BOVINOCULTURA: CARACTERIZAÇÃO DO SISTEMA PRODUTIVO NO DISTRITO MACAÚBA, ARAGUATINS (TO)
}

\author{
Aline Souza Soares* \\ Valéria Oliveira Martins** \\ Suelen dos Santos Brito****
}

RESUMO: O objetivo do trabalho foi caracterizar o sistema produtivo da pecuária de bovinos do Distrito Macaúba, Araguatins (TO). Foram aplicados questionários, abordando parâmetros sociais, econômicos e técnicos, pela obtenção de média aritmética simples, valores percentuais, taxas de natalidade e de mortalidade. Os questionários foram aplicados mediante autorização escrita dos entrevistados. A amostragem foi de vinte e nove propriedades. Verificou-se que $50 \%$ das propriedades atuam na bovinocultura de corte, $15 \%$ na bovinocultura de leite, e 35\% atuam em ambas. Verificou-se que a maioria dos responsáveis pela atividade são pequenos e médios produtores. O rebanho foi quantificado em 12.200 cabeças, alocadas em aproximadamente $\mathbf{5 . 7 6 8}$ hectares de pastagens. O controle sanitário e zootécnico do rebanho é realizado pela totalidade dos produtores e as taxas de natalidade e de mortalidade foram de $57,2 \%$ e $2 \%$, respectivamente. Identificou-se que dezesseis propriedades não realizam nenhum tipo de controle financeiro ou gerencial, que cinco já realizaram inseminação artificial, mas somente uma continua utilizando a técnica. Os produtores de gado de corte atuam principalmente na fase de cria dos animais e o principal destino dos animais de abate é o frigorífico. Na bovinocultura de leite não há utilização de tecnologias, tão pouco o uso de ordenha mecânica, sendo o principal destino do leite produzido na região a venda para o laticínio de Buriti do Tocantins. Conclui-se que, em razão das características edafoclimáticas, esta região tem grande potencial para a produção em larga escala, porém pouco explorada.

PALAVRAS-CHAVE: Agronegócio; Produção animal; Sistema produtivo.

\footnotetext{
"Mestranda em Biotecnologia pela Universidade Federal do Tocantins (UFT), Laboratório de Biologia Molecular Brasil. E-mail: bioalinesouza@gmail.com

*** Especialista em Educação Ambiental. Faculdade de Selvíria (FAS), Brasil.

*** Mestra em Ciência Animal Tropical pela Universidade Federal do Tocantins (UFT), Zootecnista pela Universidade Federal do Tocantins(UFT), Brasil.
} 


\section{LIVESTOCK: CHARACTERIZATION OF THE PRODUCTION SYSTEM IN THE MACAÚBA DISTRICT, ARAGUATINS, BRAZIL}

ABSTRACT: Current research characterizes the production system of cattle breeding in the Macaúba District, Araguatins TO Brazil. Four questionnaires comprising social, economic and technical parameters were applied to obtain a simple arithmetical mean, percentages, birth and death rates. Questionnaires were applied after authorization from participants; sampling involved 29 farms. Fifty percent of the farms deal with beef cattle, $15 \%$ with dairy cows and 35\% with both. The people involved in the activity were small- and medium-size producers. The herd comprised 12,200 cattle in approximately 5,768 h of pasture. Sanitary and animal control were undertaken by all producers, whilst birth and mortality rates were respectively $57.2 \%$ and $2 \%$. Sixteen farms do not have any financial or administrative control; five undertook artificial insemination and only one is still using the technique. Livestock producers are mainly active within the animals' breeding phase and the animals are finished at the abattoir. Dairy farms do not use any technology and mechanical milking is rare. Milk is sent to the dairy factory in Buriti do Tocantins. Results show that, due to soil-climatic reasons, the region analyzed has a great potential for large-scale production, albeit scantily exploited.

KEY WORDS: Agribusiness; Animal production; Production system.

\section{INTRODUÇÃO}

A bovinocultura é uma das principais atividades da economia brasileira, e vem ganhando destaque nos mercados interno e externo, fornecendo produtos com qualidade e em larga escala, proporcionando, assim, maior renda para o país, atuando diretamente na geração de emprego, qualidade de vida e desenvolvimento tecnológico.

As características ambientais brasileiras permitem o desenvolvimento das atividades agropecuárias com qualidade em geral, e, deste modo, se associadas a práticas adequadas para manejo dos animais, produção de pastagens, e tecnologias inovadoras, podem fornecer subsídios para grandes produções, fazendo com que o país alcance o ápice da produção. A economia brasileira é impulsionada consideravelmente pela pecuária, que movimentou mais de $\mathrm{R} \$ 483,5$ bilhões em 2015 , e representa 30\% do agronegócio brasileiro (ABIEC, 2016). O Brasil produziu 218,23 
milhões de cabeças de bovinos no ano de 2016 (IBGE, 2017), que foram comercializadas dentro e fora do país, levando o Brasil a ser detentor do maior rebanho comercial de bovinos do mundo, sendo o maior exportador mundial de carne bovina (FLORINDO et al., 2015).

O Estado do Tocantins, localizado a Sudeste da região Norte do país e tendo na pecuária um dos pilares da economia, tem se desenvolvido cada vez mais no ramo da bovinocultura, expandindo a quantidade e a qualidade do seu rebanho a fim de obter maior lucratividade. Possui 8,35 milhões de cabeças, e movimentou US\$162,2 milhões por meio da exportação da carne para mais de vinte países, especialmente da Europa e Ásia, bem como para a comercialização interna, em todas as regiões do Brasil (IBGE, 2016a; SEAGRO, 2016). O município de Araguatins, localizado no extremo Norte do Tocantins, tem uma população estimada em 34.810 habitantes, área de 2.625,286 km², e possui um rebanho bovino de 129.317 cabeças (IBGE, 2016b). O Distrito Macaúba está localizado entre Araguatins e São Bento, às margens da BR 220 - Transamazônica, a 42 km de Araguatins e conta com uma população estimada em 2.000 habitantes. O distrito é um dos centros de produção e comercialização de bovinos, que atuam tanto na bovinocultura de corte quanto na bovinocultura de leite.

Em contrapartida a este potencial produtivo, levando em consideração os níveis de produtividade de outros países, é notório que a eficiência desta atividade ainda não foi alcançada, apesar dos grandes números de produção e comercialização relacionados à atividade da bovinocultura no Brasil. Vários fatores podem contribuir para esse baixo índice de eficiência, tais como: baixos índices de reprodução, baixo potencial genético, parasitas, doenças, nutrição inadequada dos animais e degradação de pastagens (FARIA, 1999; SOUZA NETO; PEDREIRA, 2004).

O Distrito de Macaúba, assim como muitos outros distritos e regiões do extremo Norte do Tocantins, não está em condições diferentes daquelas encontradas nas demais localidades do país: ainda há muito que mudar. Apesar do grande número de bovinos no município de Araguatins, não existem dados precisos acerca das características da bovinocultura no Distrito de Macaúba, que é um importante centro de produção e comercialização destes animais na região.

O conhecimento das características do sistema de produção da pecuária 
bovina de determinada região é o aparato ideal para fornecer subsídios importantes para realizar ações que proporcionem melhorias na produção, beneficiando os produtores nos âmbitos econômicos e sociais, promovendo-lhes maior qualidade de vida. Além disso, promovem melhorias na economia do município, bem como de toda a região. Considerando estes aspectos, o presente trabalho foi estruturado, a fim de caracterizar a pecuária bovina do Distrito de Macaúba, e fornecer subsídios para futuros estudos e ações que beneficiem este setor tão importante da economia.

\section{METODOLOGIA}

\subsection{CARACTERIZAÇÃO DA ÁREA DE ESTUDO}

O trabalho foi desenvolvido no Distrito de Macaúba, município de Araguatins, no extremo Norte do Tocantins - Brasil, a $621 \mathrm{~km}$ de Palmas, capital do Estado. A região está localizada entre Araguatins e São Bento, às margens da BR 220 - Transamazônica, a $42 \mathrm{~km}$ de Araguatins. O clima predominante no Estado é tropical, caracterizando-se por estação chuvosa (outubro a abril) com temperatura média de $26^{\circ} \mathrm{C}$ e seca (maio a setembro), com temperatura média de $32{ }^{\circ} \mathrm{C}$ (MMA, 2006).

\subsection{CARACTERIZAÇÃO DA PESQUISA}

Quanto à abordagem realizada, a pesquisa científica se caracterizou como quali-quantitativa, onde se buscou quantificar os dados obtidos com objetividade, como também buscou-se a compreensão do que os dados obtidos significavam para a pesquisa (GERHARDT; SILVEIRA, 2009). O levantamento de dados foi realizado no mês de maio de 2017 , por coleta direta, através de visitas nas propriedades e aplicação de um questionário respondido por meio de entrevista com os proprietários rurais.

Estes proprietários foram entrevistados ao acaso, por amostragem não-probabilística (OLIVEIRA, 2011), buscando-se alcançar o maior número de produtores da região. A amostragem incluiu 29 (vinte e nove) propriedades visitadas, sendo que 
destas, 26 (vinte e seis) tiveram a aplicação do questionário. Quanto ao número de propriedades em que a pesquisa foi realizada, este foi encontrado por meio de conversas informais com os próprios moradores da região, tendo em vista que nenhum órgão forneceu um número exato acerca da quantidade de propriedades que atuam na produção e comercialização de bovinos no Distrito de Macaúba.

Todos os entrevistados receberam uma explicação oral e escrita acerca da pesquisa, e assinaram um termo de autorização para a divulgação dos dados obtidos, desde que os mesmos não divulguem nomes dos proprietários ou propriedades, e que os mesmos sejam utilizados somente para fins científicos.

Todas as propriedades estudadas foram pontuadas de acordo com as coordenadas geográficas obtidas. A obtenção das coordenadas foi realizada por intermédio de um aparelho GPS Esportivo Portátil Garmin Etrex 10, fornecido pelo SENAR - Regional de Araguatins.

\subsection{TABULAÇÃO DOS DADOS}

Posterior à aplicação dos questionários, realizou-se a tabulação dos dados no Microsoft Excel 2010, obtendo por meio dessa forma as quantidades totais, médias aritméticas simples e porcentagens dos resultados, além das taxas de natalidade e mortalidade do rebanho, a fim de identificar a quantidade de animais em cada ramo da atividade, bem como as características da bovinocultura da região no que tange aos índices produtivos, tecnológicos, sanitários, zootécnicos e gerenciais.

\subsubsection{Média aritmética simples}

A média aritmética simples é obtida somando todos os valores da variável e dividindo pelo número de observações (CAZORLA, 2002).

Durante o desenvolvimento desta pesquisa, a média aritmética simples foi utilizada para obter a média de leite produzido por vaca ao dia durante o ano e a média total de leite produzido por dia em cada propriedade que atua na bovinocultura de leite. 


\subsubsection{Taxa de natalidade e taxa de mortalidade do rebanho}

As taxas de natalidade e mortalidade do rebanho bovino são índices zootécnicos de grande importância para uma análise eficiente acerca da produtividade do rebanho. Essas taxas foram calculadas baseando-se no número de bezerros nascidos no período de um ano, e também no número de vacas prenhes no mesmo período, de acordo com os valores informados pelos proprietários.

Para calcular a taxa de natalidade, divide-se o número de bezerros nascidos vivos durante o ano pelo número médio mensal de vacas, e multiplicando por 100 (cem). O ideal é ter $100 \%$ de bezerros nascidos durante um ano. A taxa de mortalidade deve ser a menor possível (abaixo de 1\%). Para a bovinocultura de leite sob o sistema de pastejo, com rebanhos acima de 100 (cem) cabeças adultas, se aceita até 2\% de mortalidade destes animais (EMBRAPA, 2007).

\section{RESULTADOS E DISCUSSÃO}

\subsection{CARACTERÍSTICAS GERAIS DAS PROPRIEDADES}

Vinte e nove propriedades rurais foram visitadas, de modo que, destas, apenas vinte e seis foram analisadas por meio do questionário que serve como base para este trabalho. Não foi possível realizar a análise de três das propriedades visitadas, pois nenhum proprietário ou responsável pelo local foram encontrados para que o questionário pudesse ser aplicado.

Por meio da pesquisa de campo realizada no Distrito de Macaúba, verificou-se que há aproximadamente 12.832,56 hectares de terra em propriedades que estão envolvidas na atividade de bovinocultura de corte e de leite. Destes, 5.768,84 hectares estão destinados a pastagens (Tabela 1). 
Tabela 1. Dados gerais das propriedades atuantes na cadeira produtiva de bovinocultura do Distrito de Macaúba, Araguatins (TO)

(Continua)

\begin{tabular}{|c|c|c|c|c|c|}
\hline \multirow[t]{2}{*}{ Localização } & \multirow[t]{2}{*}{ Prop. } & \multirow{2}{*}{$\begin{array}{l}\text { Área Total } \\
\text { (hectares) }\end{array}$} & \multicolumn{2}{|c|}{$\begin{array}{c}\text { Área de } \\
\text { Pastagem }\end{array}$} & \multirow[t]{2}{*}{ Maquinários } \\
\hline & & & Hectares & $\%$ & \\
\hline $\begin{array}{l}\text { S } 05^{\circ} 43^{\prime} 48.10^{\prime \prime} \\
\text { W } 047^{\circ} 50^{\prime} 58.74 "\end{array}$ & 1 & 242,00 & 121,00 & 50,00 & Trator \\
\hline $\begin{array}{l}\text { S } 05^{\circ} 52^{\prime} 45.12^{\prime \prime} \\
\text { W } 047^{\circ} 56^{\prime} 40.65^{\prime \prime}\end{array}$ & 2 & 348,48 & 96,80 & 27,70 & Trator \\
\hline $\begin{array}{l}\text { S } 05^{\circ} 54^{\prime} 55.22 " \\
\text { W } 047^{\circ} 56^{\prime} 40.85^{\prime \prime}\end{array}$ & 3 & 106,48 & 48,40 & 45,45 & Trator \\
\hline $\begin{array}{l}\text { S } 05^{\circ} 57^{\prime} 32.13^{\prime \prime} \\
\text { W } 047^{\circ} 56^{\prime} 42.25^{\prime \prime}\end{array}$ & 4 & 285,56 & 169,40 & 59,32 & $\begin{array}{c}\text { Trator, roçadeira, sulcador, } \\
\text { semeadeira }\end{array}$ \\
\hline $\begin{array}{l}\text { S 05' } 52^{\prime} 44.09^{\prime \prime} \\
\text { W } 047^{\circ} 566^{\prime} 50.74 "\end{array}$ & 5 & 101,64 & 82,28 & 80,95 & "Não possui" \\
\hline $\begin{array}{l}\text { S } 05^{\circ} 50^{\prime} 40.2^{\prime} \\
\text { W } 047^{\circ} 59^{\prime} 60.7^{\prime \prime}\end{array}$ & 6 & 1936,00 & 726,00 & 37,50 & Trator \\
\hline $\begin{array}{l}\text { S } 05^{\circ} 50^{\prime} 31.7^{\prime \prime} \\
\text { W } 047^{\circ} 59^{\prime} 68.5^{\prime \prime} \\
\text { S } 05^{\circ} 49^{\prime} 71.8^{\prime} \\
\text { W } 047^{\circ} 59^{\prime} 75.5^{\prime \prime}\end{array}$ & $\begin{array}{l}7\left(1^{\circ} \text { retiro }\right) \\
7\left(2^{\circ} \text { retiro }\right)\end{array}$ & 2420,00 & 484,00 & 20,00 & $\begin{array}{l}\text { Trator, motosserra, pulverizador } \\
\text { costal }\end{array}$ \\
\hline $\begin{array}{l}\text { S } 05^{\circ} 49^{\prime} 35.7^{\prime \prime} \\
\text { W } 047^{\circ} 56^{\prime} 77.7^{\prime \prime}\end{array}$ & 8 & 363,00 & 179,08 & 49,33 & Trator e pulverizador costal \\
\hline $\begin{array}{l}\text { S } 05^{\circ} 53^{\prime} 38.4^{\prime \prime} \\
\text { W } 047^{\circ} 58^{\prime} 70.7^{\prime \prime}\end{array}$ & 9 & 2904,00 & 1452,00 & 50,00 & Trator \\
\hline $\begin{array}{l}\text { S } 047^{\circ} 54^{\prime} 28.0^{\prime \prime} \\
\text { W } 047^{\circ} 59^{\prime} 24.7^{\prime \prime}\end{array}$ & 10 & $\begin{array}{l}\text { "Não infor- } \\
\text { mado" }\end{array}$ & $\begin{array}{c}\text { "Não } \\
\text { informa- } \\
\text { do" }\end{array}$ & & Trator \\
\hline $\begin{array}{l}\text { S } 05^{\circ} 51^{\prime} 15.4^{\prime \prime} \\
\text { W } 047^{\circ} 58^{\prime} 68.1^{\prime \prime}\end{array}$ & 11 & 232,32 & 87,12 & 37,50 & Trator e roçadeira \\
\hline $\begin{array}{l}\text { S } 05^{\circ} 50^{\prime} 29.3^{\prime \prime} \\
\text { W } 047^{\circ} 58^{\prime} 09.1^{\prime \prime}\end{array}$ & 12 & 217,00 & 121,00 & 55,76 & Trator e roçadeira \\
\hline $\begin{array}{l}\text { S } 05^{\circ} 46^{\prime} 34.3^{\prime \prime} \\
\text { W } 047^{\circ} 57^{\prime} 03.6^{\prime \prime}\end{array}$ & 13 & 637,00 & 400,00 & 62,79 & "Não possui" \\
\hline $\begin{array}{l}\text { S } 05^{\circ} 49^{\prime} 35.7^{\prime \prime} \\
\text { W } 047^{\circ} 57^{\prime} 04.5^{\prime \prime}\end{array}$ & 14 & 246,84 & 198,44 & 80,39 & "Não possui" \\
\hline $\begin{array}{l}\text { S } 05^{\circ} 56^{\prime} 48.7^{\prime \prime} \\
\text { W } 047^{\circ} 55^{\prime} 21.8^{\prime \prime}\end{array}$ & 15 & 290,40 & 48,40 & 16,67 & "Não possui" \\
\hline $\begin{array}{c}\text { S } 05^{\circ} 55^{\prime} 35.01^{\prime} \\
\text { W } 047^{\circ} 55^{\prime} 27.06^{\prime \prime}\end{array}$ & 16 & 363,00 & 121,00 & 33,33 & "Não possui" \\
\hline
\end{tabular}


(Conclusão)

\begin{tabular}{|c|c|c|c|c|c|}
\hline \multirow{2}{*}{ Localização } & \multirow{2}{*}{ Prop. } & \multirow{2}{*}{$\begin{array}{l}\text { Área Total } \\
\text { (hectares) }\end{array}$} & \multicolumn{2}{|c|}{$\begin{array}{c}\text { Área de } \\
\text { Pastagem }\end{array}$} & \multirow{2}{*}{ Maquinários } \\
\hline & & & Hectares & $\%$ & \\
\hline $\begin{array}{l}\text { S } 05^{\circ} 54^{\prime} 47.56^{\prime \prime} \\
\text { W } 047^{\circ} 55^{\prime} 12.09^{\prime \prime}\end{array}$ & 17 & 37,80 & 30,00 & 79,37 & Trator \\
\hline $\begin{array}{l}\text { S } 05^{\circ} 56^{\prime} 19.99^{\prime \prime} \\
\text { W } 047^{\circ} 55^{\prime} 38.33^{\prime \prime}\end{array}$ & 18 & 242,00 & 169,40 & 70,00 & "Não possui" \\
\hline $\begin{array}{l}\text { S } 05^{\circ} 56^{\prime} 38.77^{\prime \prime} \\
\text { W } 047^{\circ} 55^{\prime} 89.34 "\end{array}$ & 19 & 290,40 & 72,60 & 25,00 & Trator \\
\hline $\begin{array}{l}\text { S } 05^{\circ} 39^{\prime} 05.2^{\prime \prime} \\
\text { W } 048^{\circ} 07^{\prime} 23.6^{\prime \prime}\end{array}$ & 20 & 822,80 & 774,40 & 94,12 & "Não possui" \\
\hline $\begin{array}{l}\text { S } 05^{\circ} 53^{\prime} 12.2^{\prime \prime} \\
\text { W } 047^{\circ} 58^{\prime} 33.9^{\prime \prime}\end{array}$ & 21 & 93,00 & 72,60 & 78,06 & "Não possui" \\
\hline $\begin{array}{l}\text { S } 05^{\circ} 50^{\prime} 32.9^{\prime \prime} \\
\text { W } 047^{\circ} 58^{\prime} 70.9^{\prime \prime}\end{array}$ & 22 & 67,76 & 58,08 & 85,71 & "Não possui" \\
\hline $\begin{array}{l}\text { S } 05^{\circ} 58^{\prime} 36.9^{\prime \prime} \\
\text { W } 047^{\circ} 48^{\prime} 51.9^{\prime \prime}\end{array}$ & 23 & 174,24 & 116,16 & 66,67 & "Não possui" \\
\hline $\begin{array}{l}\text { S } 05^{\circ} 55^{\prime} 36.8^{\prime \prime} \\
\text { W } 047^{\circ} 47^{\prime} 41.8^{\prime \prime}\end{array}$ & 24 & 125,84 & 58,08 & 46,15 & "Não possui" \\
\hline $\begin{array}{l}\text { S } 05^{\circ} 53^{\prime} 37.5^{\prime \prime} \\
\text { W } 047^{\circ} 48^{\prime} 41.3^{\prime \prime}\end{array}$ & 25 & 82,00 & 72,60 & 88,54 & "Não possui" \\
\hline $\begin{array}{l}\text { S } 05^{\circ} 56^{\prime} 19,99^{\prime \prime} \\
\text { W } 047^{\circ} 55^{\prime} 38,33^{\prime \prime}\end{array}$ & 26 & 203,00 & 10,00 & 4,93 & "Não possui" \\
\hline TOTAL & & 12832,56 & 5768,84 & & \\
\hline
\end{tabular}

Sete propriedades apresentaram uma porcentagem superior a $65 \%$ da área total ocupada com pastagem, indicando, em alguns casos, um descumprimento do Código Florestal Brasileiro (Lei 12.651/12), que impõe que:

Art. 12. Todo imóvel rural deve manter área com cobertura de vegetação nativa, a título de Reserva Legal, sem prejuízo da aplicação das normas sobre as Áreas de Preservação Permanentes observadas os seguintes percentuais mínimos em relação à área do imóvel, excetuados os casos previstos no art. 68 desta Lei:

a) $80 \%$ (oitenta por cento), no imóvel situado em área de florestas;

b) 35\% (trinta e cinco por cento), no imóvel situado em área de cerrado; 
c) $20 \%$ (vinte por cento), no imóvel situado em área de campos gerais;

II - localizado nas demais regiões do País: 20\% (vinte por cento) (BRASIL, 2012).

O município de Araguatins possui ambientes que variam entre os biomas Cerrado e Amazônia (IBGE, 2016b), constituindo um ecótopo, sendo, portanto, um município de transição de biomas. Neste caso, segundo a lei, há uma obrigatoriedade de reservas que variam entre 20 e 35\% da área total, de acordo com o bioma da região, e, neste caso, observou-se uma quantidade relevante de propriedades que não se enquadram nessa exigência legal.

Constatou-se também que a maioria dos proprietários não possui equipamentos necessários à manutenção da atividade, o que pode influenciar consideravelmente a produção. Instalações bem planejadas e executadas reduzem os custos de produção e tornam a mão de obra mais eficiente (SOUZA; TINOCO; SARTOR, 2003), e, para tanto, é necessário utilizar-se de equipamentos e maquinários de qualidade.

A atividade de bovinocultura no Distrito de Macaúba é realizada, de modo geral, por pequenos e médios produtores, tendo maior destaque para a bovinocultura de corte, que representou 50\% das propriedades em que o questionário foi aplicado. Além das propriedades que atuam somente na bovinocultura de corte, 15\% das propriedades atuam na bovinocultura de leite e 35\% atuam em ambas as atividades. Neste caso, grande parte dessas propriedades utiliza a pecuária de corte apenas em situações financeiras extremas, ou como forma de descarte dos animais que não alcançam níveis produtivos satisfatórios, bem como aqueles que apresentam alguma limitação física.

Quanto à gestão da propriedade, 61,53\% da amostragem pesquisada (16 propriedades) não realizam nenhum controle financeiro da atividade, o que pode comprometer significativamente o desenvolvimento da atividade, além de interferir na qualidade de vida dos próprios produtores. Segundo Frühauf (2014), a gestão financeira é um dos pontos importantes das propriedades rurais, principalmente se tratando de empreendimentos familiares, onde a produção costuma ser pequena. Nestas propriedades, porém, é visível a pouca organização das finanças e o baixo controle dos custos de produção e manutenção do negócio, o que, na maioria das 
vezes, influencia negativamente nas tomadas de decisão e acarretam graves problemas ao desenvolvimento da atividade.

\subsection{CARACTERÍSTICAS GERAIS DO REBANHO}

O Distrito de Macaúba é um importante centro de produção de gado de corte e de leite do município de Araguatins, contribuindo com aproximadamente $10 \%$ da produção total do município.

O rebanho bovino do Distrito de Macaúba conta com aproximadamente 12.200 (doze mil e duzentas) cabeças de gado, com taxa média de natalidade de $57,2 \%$ do rebanho total, e taxa média de mortalidade de $2 \%$ do rebanho total. Neste sentido, o índice de natalidade encontra-se abaixo da média e o índice de mortalidade acima da média, se comparado a outras regiões do Brasil. Índices zootécnicos na Amazônia, que apresentaram taxas de natalidade entre 48 a $78 \%$ e taxas de mortalidade de 0,5\% (SOARES-FILHO et al., 2015).

O manejo sanitário é realizado por todos os proprietários, de modo que todos os pecuaristas da região realizam a vacinação obrigatória nos meses de maio e novembro contra a aftosa e brucelose. Também fazem o controle parasitário, principalmente nos bezerros novos, e de carrapatos, de acordo com a necessidade, em tempos intercalados ao das vacinações obrigatórias.

O sistema de alimentação do rebanho é dividido da seguinte forma: 29\% das propriedades utilizam-se do sistema semi-intensivo, com animais criados em pastos e recebendo suplementação mineral no cocho, suplementação com cana e ureia e proteinado para as vacas em lactação; 59,6\% das propriedades apresentam características que as identificam em grande parte, por utilizarem o sistema extensivo, onde os animais são criados e engordados soltos em grandes áreas de pastagem, e só recebem suplemento de sal mineral; somente 11,4\% (3 propriedades) têm sistema intensivo na atividade, com o confinamento de animais para engorda.

Cardoso (1994) já conceituava o confinamento como um sistema que mantém os animais em piquetes ou currais de área restrita, de modo que o alimento e a água necessários são fornecidos em cochos, de modo que os animais levam um menor tempo para o abate. Porém, é necessário grande investimento financeiro para 
adoção deste sistema, o que explica o baixo número de produtores da região da Macaúba que possuem este sistema de alimentação, considerando o fato de que a maioria dos produtores da região é de pequeno e médio porte.

No que tange aos níveis de modernização e tecnologia aplicadas na reprodução e melhoramento genético dos animais, percebeu-se que ainda há escassez de inovações e aparatos tecnológicos para a atividade de bovinocultura. Das 26 (vinte e seis) propriedades analisadas, apenas 5 (cinco) já realizaram inseminação artificial, e, destas, apenas 1 (uma) propriedade ainda realiza este método de reprodução, onde possui atualmente cinquenta vacas inseminadas (Figura 1).

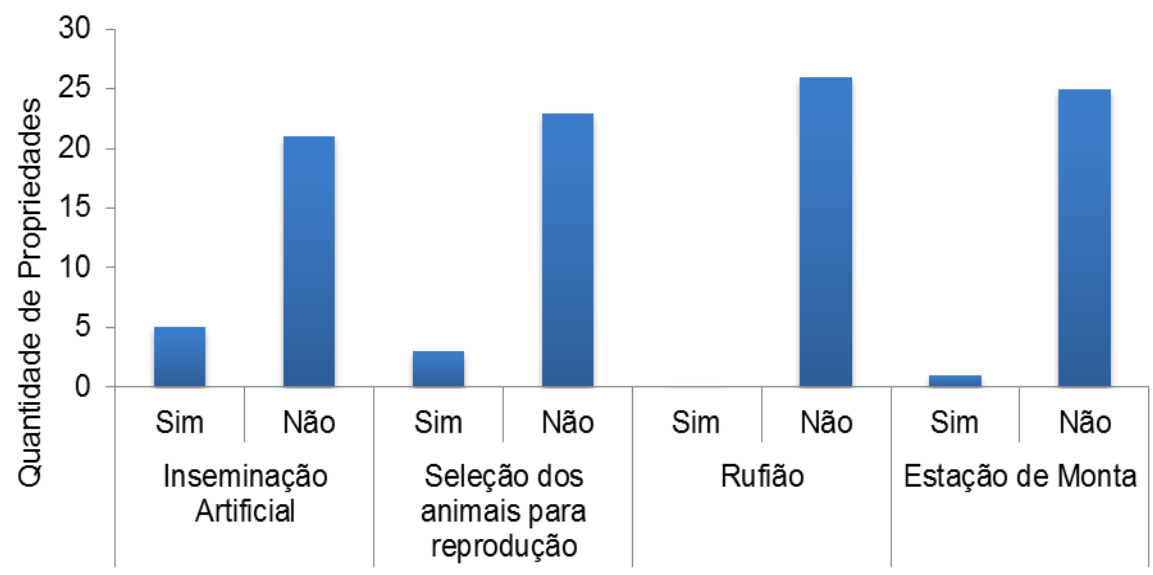

Figura 1. Panorama geral do sistema de reprodução e melhoramento genético do rebanho bovino do Distrito de Macaúba, Araguatins (TO).

Apenas 3 (três) propriedades fazem seleção de animais para reprodução, baseando-se nas características físicas e genéticas, e apenas 1 (uma) propriedade tem estação de monta. A estação de monta consiste, basicamente, em sincronizar o período de lactação das vacas do rebanho, a fim de se obter melhores índices reprodutivos (ROCHA; RATTI JÚNIOR, 2005).

No Brasil, de modo geral, o método de monta mais utilizado é aquele onde o touro permanece com o rebanho durante o ano todo, o que gera desvantagem no que diz respeito ao controle zootécnico e sanitário do rebanho, dificultando a seleção dos bovinos de maior potencial reprodutivo, em detrimento da fertilidade 
dos animais (EMBRAPA, 2005). Utilizar a estação de monta é, neste sentido, uma das primeiras medidas de manejo que devem ser implantadas quando se quer melhorar a eficiência reprodutiva (SANTOS, 2003).

Nenhuma das propriedades analisadas utiliza-se de rufião, que consistem em touros incapacitados de fecundar as fêmeas, utilizados para a identificação de vacas no cio para técnicas de reprodução assistidas, como a inseminação artificial. A falta de rufióes nas propriedades é um ponto que resulta em insegurança no que diz respeito ao monitoramento das fêmeas de reprodução, o que pode gerar maus resultados para a atividade.

Com relação às raças do rebanho, constatou-se que o Nelore tem predominância tanto na bovinocultura de corte quanto na bovinocultura de leite (Figura 2). Além desta, nas propriedades que atuam na bovinocultura de corte, as raças utilizadas foram: Caracu, Gir, Girolando, Tabapuã e Belgian Blue. Em uma das propriedades, o rebanho foi classificado como "mestiço", mas não teve a raça especificada. Percebe-se, neste caso, que a raça Girolando, caracterizada por uma raça que está apta para a produção de leite, está sendo utilizada para o abate, o que pode limitar a lucratividade das propriedades. Nas propriedades que atuam tanto na bovinocultura de corte quanto na bovinocultura de leite, além da Nelore, as raças existentes são: Girolando, Tabapuã, Jersey, Guzerá e "mestiça". Nas propriedades que atuam na bovinocultura de leite, as raças utilizadas, além da Nelore, são Girolando e Holandês.

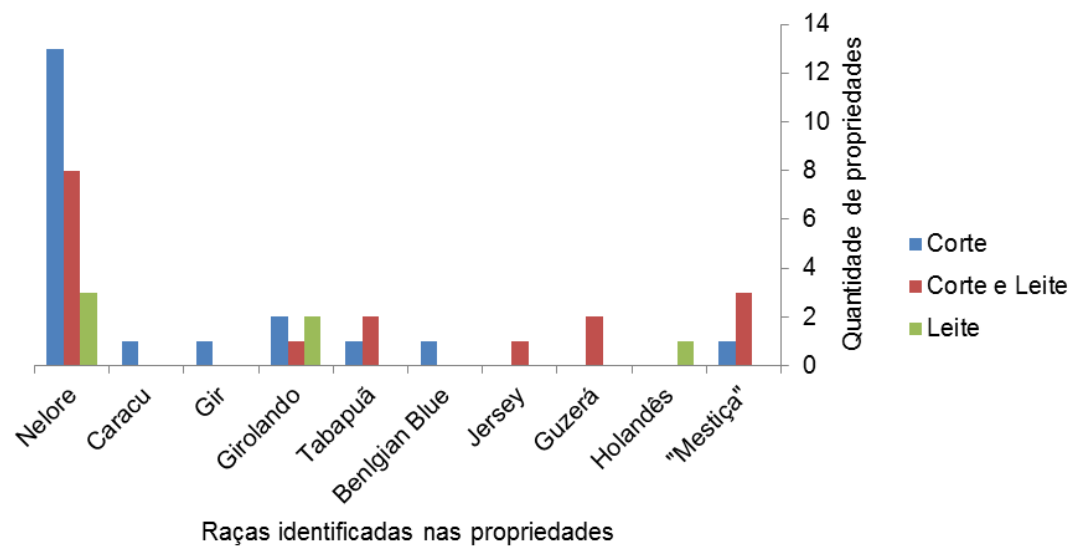

Figura 2. Raças do rebanho bovino no Distrito de Macaúba, Araguatins (TO). 
As raças, por si só, não determinam o nível de produtividade de um rebanho, porém, contribuem significativamente para este índice. Notou-se, neste sentido, que três propriedades que atuam na bovinocultura têm seu rebanho composto de gado Nelore, que é um gado mais utilizado para a bovinocultura de corte. A utilização desta raça pelos produtores justificou-se na grande maioria das vezes pela falta de conhecimento específico dos mesmos acerca da diferença do potencial produtivo entre raças. $\mathrm{O}$ baixo índice produtivo das propriedades em questão, que variam entre 1 (um) e 3 (três) litros de leite/vaca/dia reforçam a importância da utilização de raças adaptadas à produção de leite.

\subsection{BOVINOCULTURA DE CORTE}

O percentual de $35 \%$ das propriedades que atuam tanto na bovinocultura de corte como na bovinocultura de leite, e $50 \%$ das propriedades atuam somente na bovinocultura de corte, totalizando $84,62 \%$ da quantidade total de propriedades. Os dados obtidos indicaram que o perfil da bovinocultura de corte da região apresenta maior índice de produtores que atuam apenas na fase de cria dos animais, onde $42,30 \%$ das propriedades estudadas limitam-se apenas a esta fase de desenvolvimento dos animais (Figura 3).

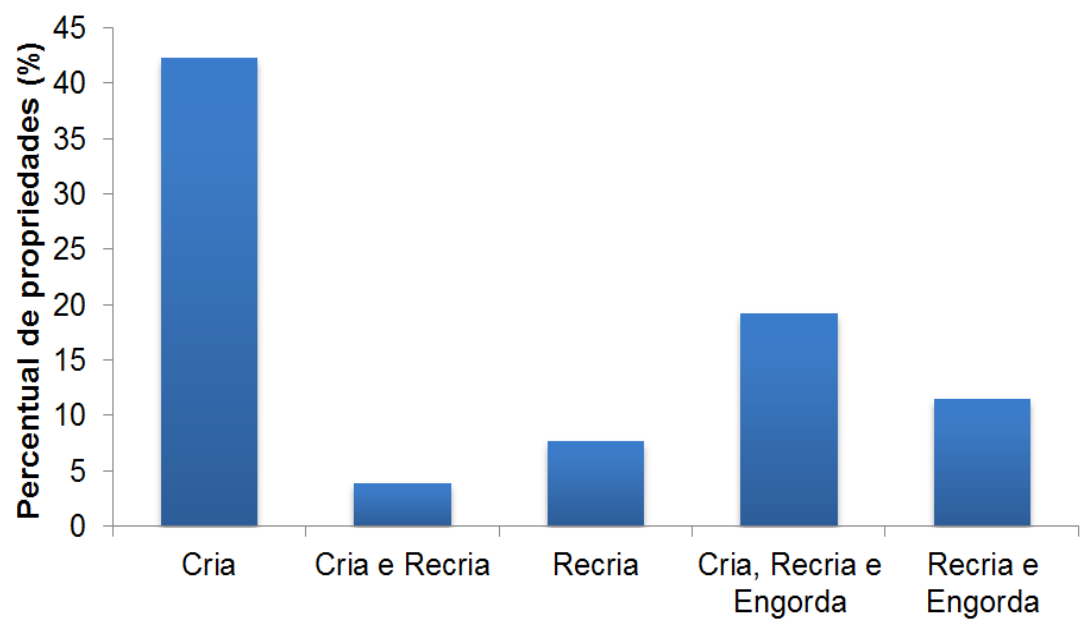

Figura 3. Fases de desenvolvimento dos bovinos nas propriedades rurais do Distrito de Macaúba, Araguatins (TO). 
Além desta, identificou-se que 3,84\% das propriedades têm animais de cria e recria; 7,69\% têm animais apenas de recria; 19,23\% das propriedades têm animas de cria, recria, e engorda, sendo que a maioria destas utiliza-se da venda dos animais para a obtenção de renda financeira de acordo com a necessidade pessoal; 11,53\% das propriedades têm animais apenas de recria e engorda.

Sabe-se que o sistema de criação intensivo, seja ele a pasto, semi-confinamento ou confinamento, demanda um grande investimento financeiro, pois o rebanho deste sistema é monitorado rigorosamente, e recebe alimentação específica, para que os animais possam ganhar peso na menor quantidade de tempo possível. Sendo assim, o perfil dos pecuaristas da região (pequeno e médio porte) explica o pouco número de propriedades que atuam nesse sistema.

Além do sistema de alimentação da região, identificou-se também o principal destino dos animais: 92,4\% são destinados aos frigoríficos e 7,6\% destinados a açougues da região. A idade média de abate do gado é de 30 a 36 meses, com o valor da arroba variando entre $\mathrm{R} \$ 100,00$ e $\mathrm{R} \$ 120,00$, de acordo com o mercado regional. A média brasileira de idade de abate é de 30 meses em sistemas tecnificados, e, sendo assim, o abate dos animais do Distrito de Macaúba está dentro da média (ZEFERINO; LUPINACCI, 2017).

\subsection{BOVINOCULTURA DE LEITE}

A média de leite produzido por vaca ao dia foi de 5,07 litros (Tabela 2), valor que se encontra muito abaixo da média nacional, que é de aproximadamente 20 litros/vaca/dia (7.570 litros/vaca/ano) em rebanhos especializados para a produção, como o gado Holandês; 12,79 litros/vaca/dia (4.670 litros/vaca/ano) no gado Jersey; e 10,38 litros/vaca/dia (3.790 litros/vaca/ano) no gado Girolando (ZOCCAL; GOMES, 2005). 
Tabela 2. Produção de leite das propriedades do Distrito de Macaúba, Araguatins (TO)

\begin{tabular}{|c|c|c|}
\hline Propriedade & Média/Vaca/Dia (lt) & Média Total/Dia (lt) \\
\hline 1 & 4 & 40 \\
\hline 2 & 5 & 90 \\
\hline 3 & 5 & 80 \\
\hline 4 & 3 & 20 \\
\hline 5 & 10 & 130 \\
\hline 6 & 8 & 50 \\
\hline 7 & 3 & 50 \\
\hline 8 & 1 & 6 \\
\hline 9 & 7 & 150 \\
\hline 10 & 4 & 20 \\
\hline 11 & 4 & 150 \\
\hline 12 & 5 & 100 \\
\hline 13 & 7 & 100 \\
\hline Total & $\mathbf{6 6}$ & $\mathbf{9 8 6}$ \\
\hline Média & $\mathbf{5 , 0 7}$ & \\
\hline
\end{tabular}

O valor médio de litros de leite produzidos ao dia foi de 986 litros, que são destinados à venda in natura e produção de queijo. Treze propriedades atuam na bovinocultura de leite, sendo quatro delas unicamente destinadas a este fim, e outras nove, que atuam na bovinocultura de corte e bovinocultura de leite. Do total de propriedades, como mostra a Figura 4, oito delas, que representam $62 \%$ da amostragem, têm como destino principal a venda para o laticínio de Buriti do Tocantins; três (23\%) destinam o leite para a produção de queijo, que é vendido por aproximadamente $\mathrm{R} \$ 10,00 / \mathrm{kg}$; duas delas $(15 \%)$ produzem e comercializam tanto o leite in natura como o queijo. 


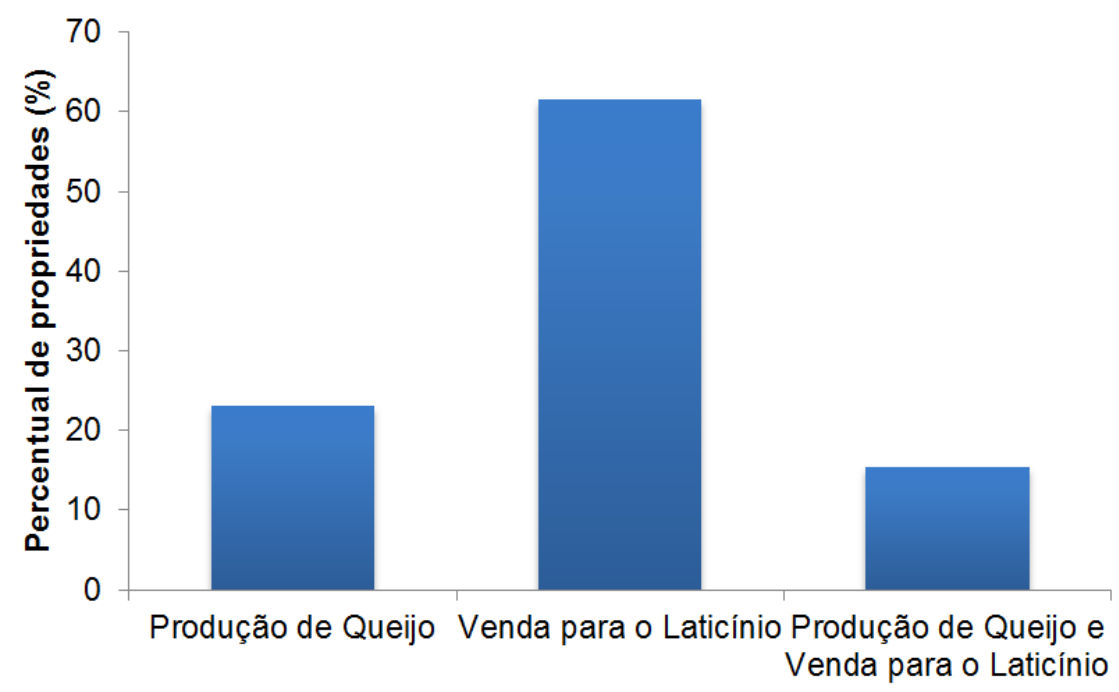

Figura 4. Principal destino do leite produzido no Distrito de Macaúba, Araguatins (TO)

O valor de venda do leite para o laticínio da região varia entre $\mathrm{R} \$ 0,85$ e $\mathrm{R} \$$ 1,10 , de acordo com a oferta do produto. Observou-se que a bovinocultura de leite da região de Macaúba encontra-se muito aquém no que diz respeito à tecnologia $\mathrm{e}$ inovação, além de utilizar-se, de modo geral, de raças bovinas não específicas para a produção de leite em larga escala. Nenhuma das propriedades analisadas possui ordenha mecânica, tanques de resfriamento, ou suplementação alimentar específica para as vacas destinadas à produção de leite. A suplementação adequada e uma boa ordenha, com os padrões sanitários e higiênicos rigorosamente cumpridos, são essenciais para obter resultados positivos na bovinocultura de leite. Através do desenvolvimento dessas atividades com qualidade, é possível obter aumento na produção, melhor qualidade do leite, menor gasto com medicamentos, além de promover melhorias para a qualidade de vida dos animais, e da propriedade como um todo (EMBRAPA, 2006). 


\section{CONCLUSÃO}

O Distrito de Macaúba é um importante centro de produção de gado de corte e de leite do município de Araguatins, tem grande potencial para um extremo crescimento produtivo, tendo em vista a grande quantidade de propriedades e de terras férteis e produtivas.

Pequenos e médios produtores predominam na atividade bovina e há carência na adoção de manejo adequado e implantação de novas tecnologias, tanto na bovinocultura de corte como na bovinocultura de leite, especialmente quanto à utilização de linhagens de animais específicas para cada tipo de atividade, o que exige maior investimento financeiro dos produtores em geral.

Sendo assim, é de extrema importância um constante estudo da atividade de bovinocultura do Distrito de Macaúba, e investimento em conhecimento, assistência técnica e tecnologia para os produtores, a fim de promover uma melhoria da produtividade, e, consequentemente, do potencial econômico no município e região.

\section{REFERÊNCIAS}

ABIEC - ASSOCIAÇÃO BRASILEIRA DAS INDÚSTRIAS EXPORTADORAS DE CARNE. Perfil da Pecuária no Brasil: Relatório Anual 2016. São Paulo. 46p. 2016. Disponível em: http://www.newsprime.com.br/img/upload2/2016_FolderPerfil_PT.pdf. Acesso em: 24 abr. 2017.

CARDOSO, E. G. A cadeia produtiva da pecuária bovina de corte. Campo Grande: EMBRAPA Gado de Corte, 1994 (Documentos no 49).

CAZORLA, I. M. A relação entre a habilidade viso-pictórica e o domínio de conceitos estatísticos na leitura de gráficos. 2002. Tese (Doutorado) - Faculdade de Educação da Universidade Estadual de Campinas, Campinas, 2002.

EMBRAPA - EMPRESA BRASILEIRA DE PESQUISA AGROPECUÁRIA. Planejamento Sanitário de Gado de Corte, 2005. Disponível em: http://www.cnpgc.embrapa.br/ publicações/. Acesso em: 26 maio. 2017. 
EMBRAPA - EMPRESA BRASILEIRA DE PESQUISA AGROPECUÁRIA. A ordenha da vaca leiteira. Comunicado Técnico 319. 4p. Porto Velho. Novembro, 2006. Disponível em: https://ainfo.cnptia.embrapa.br/digital/bitstream/item/24719/1/cot319-ordenhadavacaleiteira.pdf. Acesso em: 26 maio 2017.

EMBRAPA - EMPRESA BRASILEIRA DE PESQUISA AGROPECUÁRIA. Medidas de eficiência da atividade leiteira: índices zootécnicos para rebanhos leiteiros. Comunicado Técnico 54. 8p. Juiz de Fora. Dezembro, 2007. Disponível em: http:/ www.cnpgl.embrapa.br/totem/conteudo/Outros_assuntos/Comunicado_Tecnico/ COT54_Medidas_de_eficiencia_da_ativ_leiteira_indices_zootecnicos.p̄pdf. Acesso em: 26 jun. 2017.

FARIA, V. P. Produção de bovinos nos trópicos. In: PEIXOTO, A. M.; MOURA, J. C.; FARIA, V. P. (org.). Bovinocultura de corte: fundamentos da exploração racional. Piracicaba: FEALQ, 1999.

FLORINDO, T. J.; MEDEIROS, G. I. B. de; COSTA, J. S.; RUVIARO, C. F. Competitividade dos principais países exportadores de carne bovina no período de 2002 a 2013. Revista de Economia e Agronegócio, Viçosa, v. 12, n. 1/2/3, 2015. Disponível em: http://www.rea.ufv.br/index.php/rea/article/view/240/251. Acesso em: 25 abr. 2017.

FRÜHAUF, A. R. Gestão financeira e produtiva do empreendimento rural: uma análise da propriedade Frühauf. Centro Universitário Univates, Lajeado, 119p. 2014. Disponível em: https://www.univates.br/bdu/bitstream/10737/738/1/2014AlexandreRicardoFruhauf.pdf. Acesso em: 26 maio. 2017.

GERHARDT, T. E.; SILVEIRA, D. T. Metodologia da Pesquisa. Universidade Federal do Rio Grande do Sul - UAB/SEAD. Porto Alegre: Ed. da UFRGS, 2009. Disponível em: http://www.ufrgs.br/cursopgdr/downloadsSerie/derad005.pdf. Acesso em: 23 jun. 2017.

IBGE - INSTITUTO BRASILEIRO DE GEOGRAFIA E ESTATÍSTICA. Produção da Pecuária Municipal 2015. Rio de Janeiro, 2016a. Disponível em: http://cod.ibge. gov.br/1KAN9. Acesso em: 25 abr. 2017. 
guatins. Rio de Janeiro, 2016b. Disponível em: http://cod.ibge.gov.br/FJ3. Acesso em: 26 abr. 2017.

IBGE - INSTITUTO BRASILEIRO DE GEOGRAFIA E ESTATÍ́STICA. Produção da Pecuária Municipal. Rio de Janeiro, 2017. Disponível em: https:/biblioteca.ibge. gov.br/visualizacao/periodicos/84/ppm_2016_v44_br.pdf. Acesso em: 16 jun. 2018.

\section{MMA - MINISTÉRIO DO MEIO AMBIENTE. Caderno da Região Hidrográfica} do Tocantins - Araguaia. Secretaria de Recursos Hídricos. Brasília: MMA, 2006. Disponível em: http://www.mma.gov.br/estruturas/161/_publicacao/161_publicacao02032011035943.pdf. Acesso em: 27 jun. 2017.

OLIVEIRA, M. F. Metodologia científica: um manual para a realização em Administração. Catalão: UFG, 2011. 72p.

ROCHA, G. P.; RATTI JÚNIOR, J. Estação de Monta: algumas considerações de importância. 2005. Disponível em: http://www.beefpoint.com.br/radarestecnicos/. Acesso em: 26 maio. 2017.

SANTOS, K. J. G. et al. Estação de monta: Técnica para Melhorar e Eficiência Reprodutiva. Jornal das Cidades, São Luís Montes Belos. 2003, 3p.

SEAGRO - SECRETARIA DA AGRICULTA E PECUÁRIA. Pecuária do Tocantins. Tocantins, 2016. Disponível em: http://seagro.to.gov.br/pecuaria/. Acesso em: 25 abr. 2017.

SOARES-FILHO, B. S.; BARBOSA, F. A.; MERRY, F. D.; AZEVEDO, H. O.; COSTA, W. L. S.; COE, M. T.; BATISTA, E. L. S.; MACIEL, T. G.; SHEEPERS, L. C.; OLIVEIRA, A. R.; RODRIGUES, H. O. Cenários para a pecuária de corte amazônica. Belo Horizonte: Ed. ICG/UFMG, 2015. 53p.

SOUZA, C. F.; TINOCO, I. F. F.; SARTOR, V. Instalações para gado de leite. Centro de Ciências Agrárias. Departamento de Engenharia Agrícola. Universidade Federal de Viçosa, Minas Gerais. 31p., 2003. Disponível em: http://www.planalto.gov.br/ ccivil_03/_ato2011-2014/2012/lei/12651.htm. Acesso em: 25 maio. 2017.

SOUZA NETO, J. M.; PEDREIRA, C. G. S. Caracterização do grau de degradação de 
pastagens. In: SIMPÓSIO SOBRE MANEJO DA PASTAGEM - FERTILIDADE DO SOLO PARA PASTAGENS PRODUTIVAS, 21, 2004, Piracicaba. Anais [..]. Piracicaba: FEALQ, 2004.

ZEFERINO, C.V.; LUPINACCI, A. V. Índices de produtividade da pecuária de corte no Brasil. Parte 2/3. BEEFPOINT, 2017. Disponível em: http://www.beefpoint.com. $\mathrm{br} /$ cadeia-produtiva/conjuntura-de-mercado/indices-de-produtividade-da-pecuaria-de-corte-no-brasil-parte-23-3878/. Acesso em: 26 maio. 2017.

ZOCCAL, R.; GOMES, A. T. Zoneamento da Produção de Leite no Brasil. In: CONGRESSO DA SOCIEDADE BRASILEIRA DE ECONOMIA E SOCIOLOGIA RURAL, 43., 2005, Ribeirão Preto. Anais [...]. Ribeirão Preto; FEARP/USP, 2005. Disponível em: http://www.sober.org.br/palestra/2/773.pdf. Acesso em: 26 maio. 2017.

Recebido em: 25/11/2017

Aceito em: 20/07/2018 